\title{
Manometric study of the sphincter of Oddi in patients with and without common bile duct stones
}

\author{
E DE MASI, E CORAZZIARI, F I HABIB, B FONTANA, V GATTI, \\ G F FEGIZ, AND A TORSOLI
}

From the Cattedra di Gastroenterologia, and II Clinica Chirurgica, University of Rome, Rome, Italy

SUMMARY Motor activity of the sphincter of Oddi has been evaluated in 34 patients who underwent ERCP examination. Manometric recordings from the common bile duct and the sphincter of Oddi were performed with a polyethylene triple lumen catheter. At ERCP 16 patients had undamaged biliary ducts; six had undergone cholecystectomy and six had gall bladder stones; 18 patients had common bile duct stones; nine of whom had undergone cholecystectomy, and seven had gall bladder stones. Length and amplitude of the resting sphincter pressure as well as frequency, duration, amplitude, and propagating pattern of phasic contractions did not significantly differ in patients with and without common bile duct stones. Sphincter of Oddi motor activity did not appear to be influenced by the variation in the diameter of the common bile duct or by previous cholecystectomy.

Sphincter of Oddi motor activity in man has been estimated using a single lumen catheter introduced postoperatively through the common bile duct, ${ }^{1}$ or more recently, via endoscopy during endoscopic retrograde cholangiopancreatography (ERCP). ${ }^{2-6}$ An increased frequency of retrograde sphincter contractions has been reported in patients with choledocolithiasis ${ }^{7}$ suggesting that an altered sphincter of Oddi motor pattern might contribute to the retention or development of common bile duct stones or both.

The aim of this study was to measure and comparatively evaluate sphincter of Oddi motor activity via endoscopy and by means of a subminiaturised triple lumen catheter in patients with and without common bile duct calculi.

\section{Methods}

\section{MANOMETRIC RECORDING}

In this study we used a polyethylene triple lumen catheter, $200 \mathrm{~cm}$ in length, having an outer diameter of $1.7 \mathrm{~mm}$ and luminal diameter of $0.5 \mathrm{~mm}$ (Med Tech Inc, Watertown, Mass, USA). Each lumen ended with a $0.5 \mathrm{~mm}$ side hole and the three orifices were spaced $2 \mathrm{~mm}$ apart. The most distal

Address for correspondence: Enrico Corazziari, MD, Cattedra di Gastroenterologia, II Clinica Medica, Policlinico Umberto I, 00161 Roma, Italy.

Received for publication 23 June 1983 orifice was $5 \mathrm{~mm}$ from the catheter tip. Starting from the most proximal orifice, the tip was marked by black rings $2 \mathrm{~mm}$ apart to permit endoscopic observation of the depth of the catheter insertion into the sphincter of Oddi. The catheter was passed through the biopsy channel of a fibreoptic endoscope (Olympus JF 1T). The intraduodenal pressure recording was obtained by a single lumen polyvinyl catheter with an outer diameter of $1.7 \mathrm{~mm}$ and an inner diameter of $0.8 \mathrm{~mm}$, taped to the endoscope, so that its recording orifice was $4 \mathrm{~mm}$ proximal to the biopsy channel opening. Each manometric catheter was infused continuously with bubble-free water at a rate of $0.5 \mathrm{ml} / \mathrm{min}$ by a minimally compliant hydraulic capillary infusion system (Arndorfer Inc, Grove Terrace, Wisconsin, USA). The intraluminal pressures were transmitted to Statham P $23 \mathrm{Db}$ transducers and recorded by a multichannel polygraph DR 8 (Electronics for Medicine, White Plains, USA) on photosensitive paper which ran at a constant rate of $2.5 \mathrm{~mm} / \mathrm{sec}$.

\section{PATIENTS}

In a six month period 85 patients underwent ERCP examination for recurrent upper abdominal pain and suspected biliary or pancreatic diseases. Sixteen patients (nine women and seven men) with a mean age of 46 years (range 25-70 years) had undamaged biliary ducts, no alteration of the biliary tract being found. The choledocus did not exceed $8 \mathrm{~mm}$ in 
diameter and the contrast medium flowed rapidly from the common bile duct into the duodenum; six patients had undergone a cholecystectomy and two had gall bladder stones. Eighteen patients (14 women and four men) with a mean age of 56 years (range 25-83 years) had common bile duct stones; nine patients had undergone cholecystectomy and seven had gall bladder stones.

\section{PROTOCOL OF THE STUDY}

Immediately before endoscopy all patients were sedated with diazepam (10-20 mg iv). After completion of the ERCP examination the manometric catheter was inserted through the endoscope, the papilla recannulated and the common bile duct entered. The manometric catheter was introduced into the common bile duct to record intracholedocal pressure, and then withdrawn across the sphincter of Oddi in $2 \mathrm{~mm}$ step increments using the black marks on the catheter as a reference for measurement. At each section recordings were obtained for at least 30 seconds. Continuous monitoring of the sphincter of Oddi with the three manometric side-holes simultaneously recording from the sphincteric high pressure zone was performed for $5.5 \pm 0.5$ minutes. During pressure recording the catheter position was monitored continuously through the endoscope by observing the position of the catheter marks relative to the papillary orifice. At the end of the manometric procedure contrast medium was introduced through one of the lumens of the catheter to verify that the catheter was correctly positioned in the common bile duct.

\section{ANALYSIS OF DATA}

Sphincter of Oddi pressures were recorded as $\mathrm{mmHg}$ with duodenal pressure as zero reference. Sphincter of Oddi pressure recordings were divided into one minute periods and maximal basal midinspiratory pressure as well as amplitude and duration of phasic contractions were measured at the level of the middle recording orifice. The propagating pattern of phasic contractions was examined by analysing the three recording sites. For statistical evaluation of data, the paired Student's $t$ test and correlation analysis were used.

\section{Results (Table)}

PATIENTS WITH UNDAMAGED BILIARY DUCTS Sphincter of Oddi mean maximal resting pressure was $18.8 \pm 3.6 \mathrm{mmHg}(\mathrm{M} \pm \mathrm{SEM})$ above duodenal pressure. Mean extension of sphincter of Oddi basal pressure was 9.9 \pm 0.5 ; (range 8-14 $\mathrm{mm}$ ). Monophasic waves superimposed on basal tone could be evaluated in 13 patients, while three patients had an irregular pattern. Mean frequency of the monophasic waves was $2.9 \pm 0.6$ contractions/ minute; mean amplitude $104 \pm 15 \mathrm{mmHg}$; mean duration $6: 4 \pm 0.5$ seconds. In nine patients monophasic waves within the sphincter of Oddi appeared simultaneously (Fig. 1) at the three recording levels with a frequency of $2 \cdot 0 \pm 0 \cdot 3$ contractions/minute. Monophasic waves propagating in a retrograde fashion (Fig. 2) were recorded in five patients with a frequency of $0 \cdot 3 \pm 0 \cdot 1$ contractions/minute. Monophasic waves propagating in an anterograde fashion (Fig. 3) were detected in two patients and had a frequency of $0.5 \pm 0.4$ contractions/minute.

PATIENTS WITH COMMON BILE DUCT STONES Sphincter of Oddi mean maximal resting pressure was $17.3 \pm 2.9 \mathrm{mmHg}$ above duodenal pressure. Mean extension of sphincter of Oddi basal pressure was $9.5 \pm 0.8 \mathrm{~mm}$; (range $5-14 \mathrm{~mm}$ ). Monophasic waves superimposed on basal tone could be evaluated in 13 patients, as the phasic contractions had an irregular pattern in one patient and were absent in four patients. Mean frequency of the monophasic waves was $4.0 \pm 0.6$ contractions/ minute, mean amplitude $101 \pm 11 \mathrm{mmHg}$, mean duration $6 \cdot 3 \pm 0.4$ seconds. Monophasic waves appeared simultaneously at the three recording sites within the sphincter of Oddi in 10 patients with a frequency of $3.0 \pm 0.8$ contractions/minute, monophasic waves propagating in a retrograde fashion were recorded in five patients with a frequency of

Table Manometric variables of the sphincter of Oddi

\begin{tabular}{|c|c|c|c|c|c|c|c|c|}
\hline & \multicolumn{2}{|c|}{ Basal pressure } & \multicolumn{6}{|c|}{ Phasic contractions } \\
\hline & $\begin{array}{l}\text { Length } \\
(\mathrm{mm})\end{array}$ & $\begin{array}{l}\text { Max pressure } \\
\text { (mmHg) }\end{array}$ & $\begin{array}{l}\text { Frequency } \\
\text { waves } / \mathrm{min}\end{array}$ & $\begin{array}{l}\text { Amplitude } \\
\text { (mmHg) }\end{array}$ & $\begin{array}{l}\text { Duration } \\
\text { (sec) }\end{array}$ & $\begin{array}{l}\text { Simult } \\
\text { w/min }\end{array}$ & $\begin{array}{l}\text { Retrogr } \\
\text { w/min }\end{array}$ & $\begin{array}{l}\text { Anterog } \\
w / \min \end{array}$ \\
\hline $\begin{array}{l}\text { CBDS } \\
\text { UBD }\end{array}$ & $\begin{array}{l}9 \cdot 5 \pm 0.8 \\
9.9 \pm 0.5\end{array}$ & $\begin{array}{l}17 \cdot 3 \pm 2 \cdot 9 \\
18 \cdot 8 \pm 3 \cdot 6\end{array}$ & $\begin{array}{l}4 \cdot 0 \pm 0 \cdot 6 \\
2 \cdot 9 \pm 0 \cdot 6\end{array}$ & $\begin{array}{l}101 \pm 11 \\
104 \pm 15\end{array}$ & $\begin{array}{l}6 \cdot 3 \pm 0.4 \\
6 \cdot 4 \pm 0.5\end{array}$ & $\begin{array}{l}3 \cdot 0 \pm 0 \cdot 8 \\
2 \cdot 0 \pm 0 \cdot 3\end{array}$ & $\begin{array}{l}0.4 \pm 0 \cdot 1 \\
0.3 \pm 0 \cdot 1\end{array}$ & $\begin{array}{l}0.1 \pm 0.1 \\
0.5 \pm 0.4\end{array}$ \\
\hline
\end{tabular}

$\mathrm{M} \pm \mathrm{SEM}$.

CBDS: common bile duct stones; UBD: undamaged biliary ducts. 
Fig. 1 Manometric recording with triple lumen catheter (proximal, middle, distal) from sphincter of Oddi and with single lumen catheter from duodenum. Simultaneous phasic contractions at three levels of sphincter of Oddi. Calibration in $\mathrm{mmHg}$.
Fig. 2 Manometric recording with triple lumen catheter (proximal, middle, distal) from sphincter of Oddi and with single lumen catheter from duodenum. On left phasic contractions propagating proximally. Calibration in $\mathrm{mmHg}$.
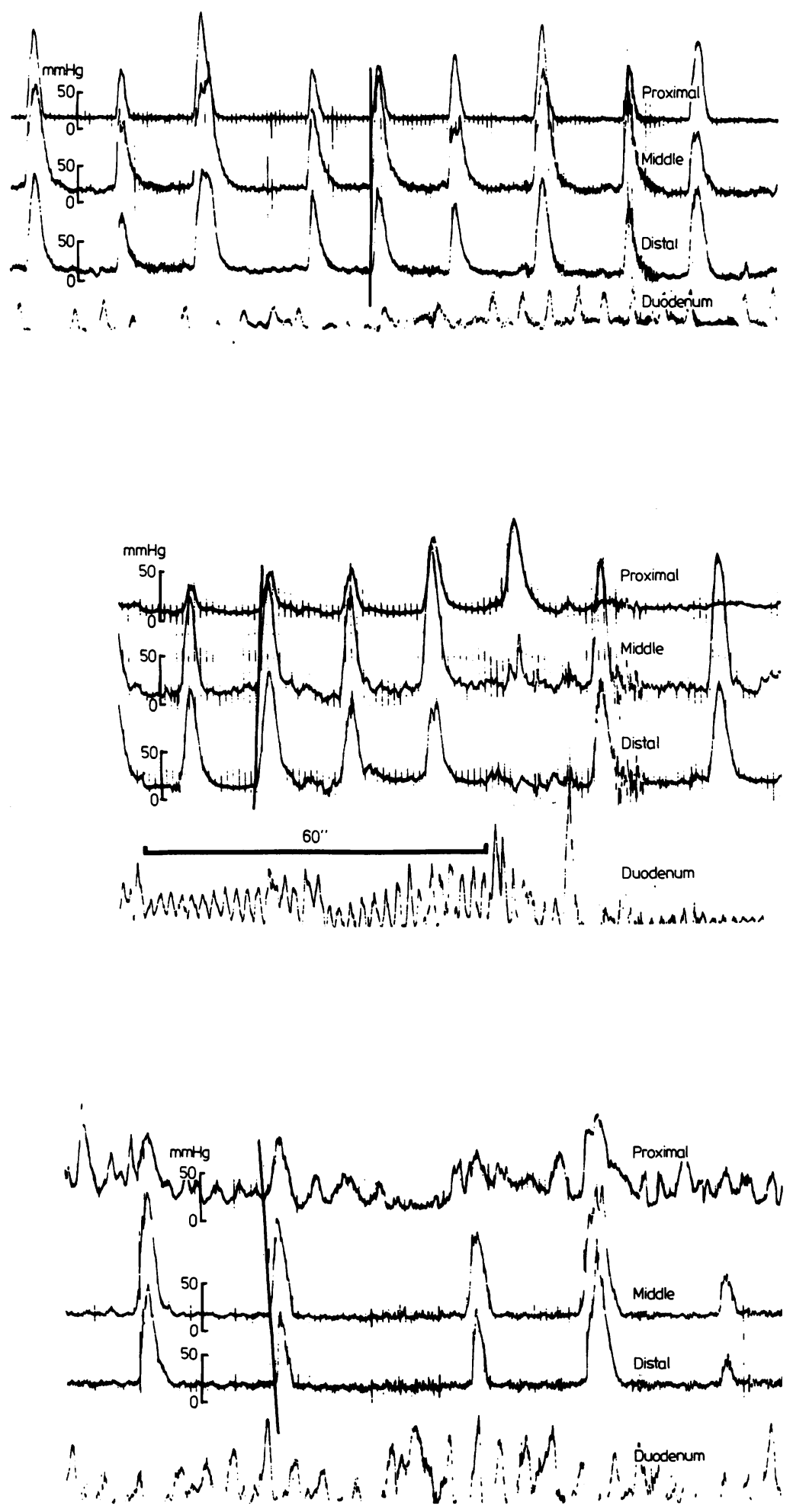

Fig. 3 Manometric recording with triple lumen catheter (proximal, middle, distal) from sphincter of Oddi and with single lumen catheter from duodenum. On left phasic contractions propagating distally. Calibration in $\mathrm{mmHg}$. 
$0 \cdot 4 \pm 0 \cdot 1$ contractions/minute. Monophasic waves propagating in anterograde fashion were recorded in one patient with a frequency of $0 \cdot 1 \pm 0 \cdot 1$ contractions/minute. No correlation was found between either resting or phasic pressure of the sphincter of Oddi and the diameter of the common bile duct.

\section{CHOLECYSTECTOMISED PATIENTS}

Sphincter of Oddi mean maximal resting pressure as well as mean frequency, amplitude, duration, and propagating pattern of phasic contractions in cholecystectomised patients did not differ significantly from non-cholecystectomised patients.

\section{Discussion}

Using a miniaturised catheter sphincter of Oddi motor behaviour appears to be characterised by distinct tonic and phasic pressure activity occurring in relatively constant patterns. Manometry of the sphincter of Oddi makes it possible to evaluate these parameters as well as the extension of the sphincter.

Phasic pressure variations occur at different sites of the sphincter so that simultaneous recording from at least two sites within the sphincter of Oddi allows the estimating of their time-space relationships, and thus the eventual distal or proximal propagation.

Previous investigations reported either no difference in sphincter of Oddi motor activity in patients with and without cholelithiasis ${ }^{2}$ or an increased frequency of retrograde sphincter contractions in patients with common bile duct stones. ${ }^{7}$

In this study patients with and without common bile duct stones show no difference in sphincter of Oddi basal pressure and sphincter of Oddi phasic contractions (amplitude, duration, and propagating pattern). Frequency of phasic contractions was higher but the difference was not statistically significant.

The results would therefore indicate that motor activity of the sphincter of Oddi does not play a significant role in the formation and/or retention of common bile duct stones and, conversely, the presence of calculi within the choledocus does not induce any relevant variation in the sphincter of Oddi motility. Statistical analysis of these data would also indicate that variation in the diameter of the common bile duct and the absence of the gall bladder do not induce significant variations in the resting and phasic pressure of the sphincter of Oddi.

This study was supported by CNR grant no 81.00084.04.

\section{References}

1 Texter EC, Chou CC, Laureta HC, Vantrappen GR. In: Physiology of the gastrointestinal tract. Saint Louis: C V Mosby, 1968: 125-6.

2 Csendes A, Kruse Z, Funch-Jensen P, Øster MJ, $\emptyset$ rnsholt J, Amdup E. Pressure measurements in the biliary and pancreatic duct system in control and in patients with gallstones, previous cholecystectomy or common bile duct stones. Gastroenterology 1979; 77: 1203-10.

3 Geenen JE, Morgan WJ, Dodds WJ, Stewart ET, Arndorfer RC. Intraluminal pressure recordings from the human sphincter of Oddi. Gastroenterology 1980; 78: 317-24.

4 Carr-Locke DL, Gregg JA. Endoscopic manometry of pancreatic and biliary sphincter zones in man: basal results in healthy volunteers. Dig Dis Sci 1981; 26: $7-15$.

5 Torsoli A, Corazziari E, De Masi E. Motility of the human biliary tree. Presented at International Symposium on Bile Acids, Cortina, March 1982. In: Barbara L, Dowling RH, Hofmann AF, Roda E, eds. Bile acids in gastroenterology. Lancaster: MTP Press, 1983: 144-51.

6 Corazziari E, De Masi E, Gatti V, Habib FI, De Simone A, Primerano L, Torsoli A, Fegiz G. Caerulein and sphincter of Oddi pressure activity. Ital J Gastroenterol 1982; 14: 239-41.

7 Toouli J, Geenen JE, Hogan WJ, Dodds WJ, Arndorfer RC. Sphincter of Oddi motor activity: a comparison between patients with common bile duct stones and controls. Gastroenterology 1982; 82: 111-7. 